I realised that she had gone into fibrillation and should be readmitted to hospital.

Readmission proved difficult as both her surgeon and the senior registrar were absent. After a significant delay she found herself once again in the high dependency unit. She was told that she was anaemic and blood was needed, which took around 16 hours to arrive. I insisted that since she had attended the hospital as a cardiac emergency she should be seen by a consultant. But when the consultant physician arrived he refused to examine her because she had been seen by one of his colleagues on a previous visit.

Then another consultant remonstrated with her for not informing him who she had seen previously. It was quite clear that they had not read her notes. They told me she was a difficult woman and I just said: "Don't you think you would be a little uptight in the circumstances?"

The point is that during all this time no one gave her a full examination. She was once again discharged, but the pain was getting out of control. I asked my own general practitioner to see Alma. He spent 45 minutes with her and observed a swelling under her arm. When she returned to hospital a chest scan showed that in just a few weeks Alma's chest cavity had been filled by a mass of tumour. In hindsight I realised that the pressure of the tumour on her heart probably caused her cardiac problems.

Alma's treatment in hospital was costing her insurance company thousands of pounds. To this day I cannot understand why:

- She was allowed to collapse four times in two days

- She could wait for hours, sometimes a whole day, to see a doctor or have an $x$ ray examination

- No one took serious note of her food intake, or lack of it, during her stay

- She was almost sent home with severe constipation

- Blood took 16 hours to arrive

- A consultant failed to read her notes and then blamed her for not providing full information.

Alma saw one of the country's top thoracic surgeons and I do not doubt that she had first class treatment from him. The trouble with being in the private wing of a teaching hospital is that there is no resident medical officer, and the ward sister is in attendance Monday to Friday, 9 am to $5 \mathrm{pm}$, so initially out of hours or weekend problems are dealt with at a junior level.

The hospital's top administrative staff have told me that they have had an in depth inquiry, that reprimands have been issued, and that they are changing their procedures. Anyone admitted for major surgery in future will be admitted in the care of a consultant physician. A few people may recognise themselves in this account, others may reflect that "There but for the grace of God go I." But I hope that our experience will remind all in the medical sector that consideration for the patient as a human being should be paramount.

\title{
The price of truth
}

\author{
Graham Pink
}

"Truth," wrote Emily Dickinson, "is such a rare thing, it is delightful to tell it." I cannot agree. Telling the truth of what I witnessed and was unwillingly party to has been a wretched, distressing, and costly business.

For three years, from August 1987, I worked as a charge nurse on night duty with overall responsibility for the care of 72 desperately ill and dying men and women on the short stay, medical, and geriatric wards at Stepping Hill Hospital, Stockport. Patients were admitted only if critically ill from a stroke, heart attack, chest infection, kidney failure, cancer, other life threatening illness, or, more usually, a combination of such conditions. Those few able to move alone were liable to wander. Often patients would end up on the floor and injure themselves. Incontinent patients required regular bed changes; the rest needed frequent toileting during the night.

On admission most were in shock, frightened, and often in despair. A sick or disabled spouse left alone at home would give them cause for great concern and worry. Others were completely alone in the world, perhaps grieving over the loss of a lifetime partner or in fear of impending death. Each was highly dependent. For example, the statistics for ward A14 (a 26 bed male ward) show that on average in 1989 each night over seven patients $(28 \%)$ fell into category III (highly dependent) and 11 patients (42\%) were in category IV (totally dependent). Total dependency means all care with feeding, hydration, turning, toileting, medication, treatment, close observation, etc. A typical handover report would contain liberal use of such words as incontinent, confused, unconscious, paralysed, distressed, aggressive, depressed, collapse, suicidal, moribund, very poorly, fell out of bed today, anxious, dysphagia, dementia, observe closely, wanders, vomiting, and tender loving care-an inelegant and often totally inappropriate euphemism. General vigilance during the day can be helped out by visitors, doctors, cleaners, student nurses, other professional staff such as physiotherapists, and the one or two alert patients. At night almost all of these people are absent.

\section{How many nurses?}

How many nurses do you think should be on duty in a 26 bedded ward for an 11 hour shift? Throughout the day three or four nurses with as many nursing auxiliaries would on average be on duty, with some reduction for the evening period. Additionally, junior doctors spend a great deal of time on the ward during the day, as do social workers, clergy, voluntary workers, and so on. While the activity does reduce on some hospital wards at night, this is not the case on a ward for short stay care of the elderly where, on top of the mass of usual care, lonely, restless, and fearful patients lie awake and need attention. Even those wanting and able to sleep are disturbed by the amount of noise and movement.

Soon after the position became generally known the Nursing Times submitted my descriptions of life on the ward to an independent expert, a nurse academic, to assess the nurse to patient ratios. She pointed out that the concentration of all over $75 \mathrm{~s}$ in one area "creates a highly intensive care ward and it is unlikely that the needs of these patients were much reduced at night." Her recommendation was a minimum staff cover of six-preferably four nurses and two auxiliariesthough eight (five nurses) was to be preferred if standards of nursing care were to be improved and maintained. Most reasonable people, and all experienced nurses, would agree, especially when you 
realise that for $40 \%$ of the night two of the six would be on breaks. I accept that the ideal situation seldom exists so, say, three nurses and two helpers could manage on most nights allowing time to cope with the regular emergency admissions, cardiac arrests, blood transfusions, heart monitors, drug administration, toileting, turning the unconscious, and calming the deranged. There might still be little or no time to hold the hand of the 90 year old woman dying alone, console distraught relatives, and sit and comfort the lonely.

\section{"Time's glory is to calm contending kings, To unmask falsehood, and bring truth to light." \\ -The Rape of Lucrece, William Shakespeare}

But clearly, we, the professional carers, are out of touch in today's market led NHS. Our managers, both lay and to their everlasting shame nurse, know what is best-so they allocated not four nurses but one, with two untrained, unqualified assistants to struggle through the night. Perhaps lay managers can be partially excused such unthinking, uncaring decisions, but not nurse managers. How they can justify their action is quite beyond me. Had I been in a management position I would have moved heaven and earth to provide more staff and in the end resigned rather than accept the unacceptable.

The result was that procedures had to be rushed, skimped, or at times abandoned. Instead of regular monitoring of patients having a blood transfusion, for example, we would record the blood pressure, temperature, and pulse now and again-a dangerous practice. The drug round was usually carried out alone with the inevitable increased possibility of error. Interruptions occurred every few minutes-the telephone, the doctor wanting help, an anxious relative to speak to, a commode required, a patient climbing or falling out of bed, a vomiting patient. Elderly people do not want to be rushed, but we had often to rush and browbeat in a disturbing and cavalier manner-as upsetting to the nurse as it must have been for the patient. But it is the particular and individual incidents which are so vivid in my memory.

\section{A sickening incident}

It was $1145 \mathrm{pm}$ and I was alone on C5 ward-alone with 20 stricken, very ill, and dying female patients. The one auxiliary had left the ward for her first break. Two ladies were on commodes and a third called me. As I pulled and jerked Mrs G, a heavy patient who had had a stroke, toward the edge of the bed where I could drop her on to the commode, I heard footsteps shuffling unsteadily along. Pulling back the curtain I saw Mrs $\mathrm{N}$, an 86 year old woman with senile dementia, about to leave the ward. Immediately outside was a steep flight of stairs. Should I abandon Mrs G, knowing that she might fall heavily to the floor, or leave a very disoriented woman to wander so close to danger? Realising that the former was less life threatening, I rushed out of the ward to catch Mrs N. The door closed behind me, leaving 19 patients out of sight. My white coat and reassuring words meant nothing to the poor, deranged patient. In her irrational state she could not be talked back into the ward and I was compelled to take hold of her. She thought that I was a burglar in her own home and tried to fight me off. Such unseemly and gratuitous violence served only to frighten and upset her.
I cannot describe my revulsion and disgust at this episode. That I was so ill treating an elderly patient caused her distress and me shame. How I impelled that innocent woman back into the ward would be as distasteful to recount as it was loathsome to execute, and I was forced to conclude that those in authority who accepted the inadequate staffing cover not only insulted and affronted patients and staff but shamed themselves and their profession.

For a year I reported the consequences of such gross understaffing to my managers and to the health authority but no one was interested. I expressed my admiration for colleagues who always worked "with quiet dignity and sublime skill beyond the call of duty." I asked for just one more nurse on each of the three wards. This might have enabled us to provide a basic minimum level of reasonable care, though we might not be able to prevent a patient being left to lie in her own excrement for half an hour, or have time to comfort the frightened, give solace to bereaved relatives, sit with those close to death, and generally minister to the sick in the way that I learnt 40 odd years ago was my duty and privilege. It is worth noting that just along the corridor from our area was the designated intensive care unit, but never during all my time at the hospital were any of our patients transferred there no matter how ill they were, though some might well have been saved had admission been allowed. While we had one nurse to 26 patients, the intensive care unit had one nurse to one patient.

\section{The absent consultants}

My profound concern at what was going on at night had been made known to the night nurse manager since the summer of 1988 but she seemed unconcerned. In August 1989, after two years in post, I wrote to the health authority chairman detailing our situation and requesting his intervention, but it soon became clear that my descriptions of life, and more to the point death, on the old people's wards did not particularly interest him. The same applied with the three consultant geriatricians to whom I wrote. The apparent total lack of interest in the care of their patients at night was most surprising and has never been explained. Had they visited the wards they might have been moved (or shamed) to act. Once the consultants received my detailed account of the nightly neglect, I fully expected all three to arrive hotfoot if only to discredit me and disprove the reported state of affairs. As it was, never once in three years did I or anyone else see a consultant come on to a ward at night. Considering that we nursed the patients for close on half their time in hospital this complete and callous disinterest is beyond all understanding.

At any one time on a geriatric ward several patients are confused. With us this varied from vagueness and mild memory loss to outright aggression and violence. Such behaviour had several detrimental results. A patient moaning or shouting out could keep awake most of the other patients who, in turn, needed extra care, comfort, and attention. More disturbed people (for whom sedation was inappropriate or had proved ineffectual) became restless and irascible. For their own and others' protection such patients had to be moved into the corridor while one of us sat by to attempt restraint. One night I sat with a man in great torment from $1130 \mathrm{pm}$ to nearly 7 am while my usual work was largely neglected.

\section{Dying alone}

Although designated a short stay area, we regularly had several patients who were terminally ill. In 1988 , for example, of 981 people admitted to ward A14, 261 
$(27 \%)$ died on the ward. Thus, on average, at any one time seven patients were dying. Some arrived close to death; others deteriorated over a period of weeks. Care of the dying should be a special field of nursing calling for additional training and exceptional qualities. During my three years on these wards no specialist training was provided. We were expected to provide not only for the patients' physical needs but for their emotional and psychological needs. This was rarely possible because you need time. What particularly saddened and disturbed me were those frequent occasions when someone was about to die but no friend or relative was present. The comfort of a held hand, a gently caressed cheek, or quiet word of solace is incalculable but, too often, was not offered-we did not have the staff. To find that a patient had died alone because we were so short staffed caused me profound anguish and I have wept.

Starting in the autumn of 1989 , as conditions deteriorated, I wrote to the health authority chairman; the chief nurse of the hospital; the day and night nurse managers (geriatrics); the three consultant geriatricians in the hospital; the two local members of parliament; the then chief executive of the NHS, Mr (now Sir) Duncan Nichol; the Department of Health; the secretary of state for health, Mr Kenneth Clarke; the registrar of the United Kingdom Central Council for Nursing, Midwifery and Health Visiting (UKCC), the nurses' regulatory body, $\mathrm{Mr}$ Colin Ralph, who did not respond to any of my letters; the chairman of the regional health authority; the chief executive of the Stockport Health Authority; the hospital manager; the authority's chief nursing officer; the 16 members of the health authority; the health service commissioner (the ombudsman); and the prime minister. For well over seven months I tried quietly within the health service to seek help. Above all I did not want the matter to become public. The idea of going public had not crossed my mind before the one meeting I had with the assistant manager (the chief nurse) in October, when he made it clear that on no account was I to report what was going on to anyone outside the hospital. But it became obvious that no one within the hospital or health service was the least bit interested.

\section{"No one should die alone in hospital. But it happened so often and will happen again tonight."}

Perhaps to those in authority this was acceptable, nothing out of the way. Never having been given the opportunity to speak to them, I do not know. But it was not acceptable to me. It was a disgrace that these patients, who had served their families, their communities, and their country throughout the second world war should be neglected in so shameful a way. In their last days and hours our senior citizens deserve close, personal attention and loving care from sufficient nurses and assistants who have the time to carry out their work in a calm and dignified mannernot the noisy, stressful, and furious way we were often obliged to rush to get the work done. No one should die alone in hospital. But it happened so often and will happen again tonight.

My 43 letters ( 30000 words) had achieved nothing and it was now spring 1990. At a meeting with a local councillor I was advised to speak to $\mathrm{Mr}$ Andrew Bennett, another local member of parliament. He seemed most concerned-the first person to show any interest. He kindly said that my efforts to improve staffing were quite remarkable and way beyond any-

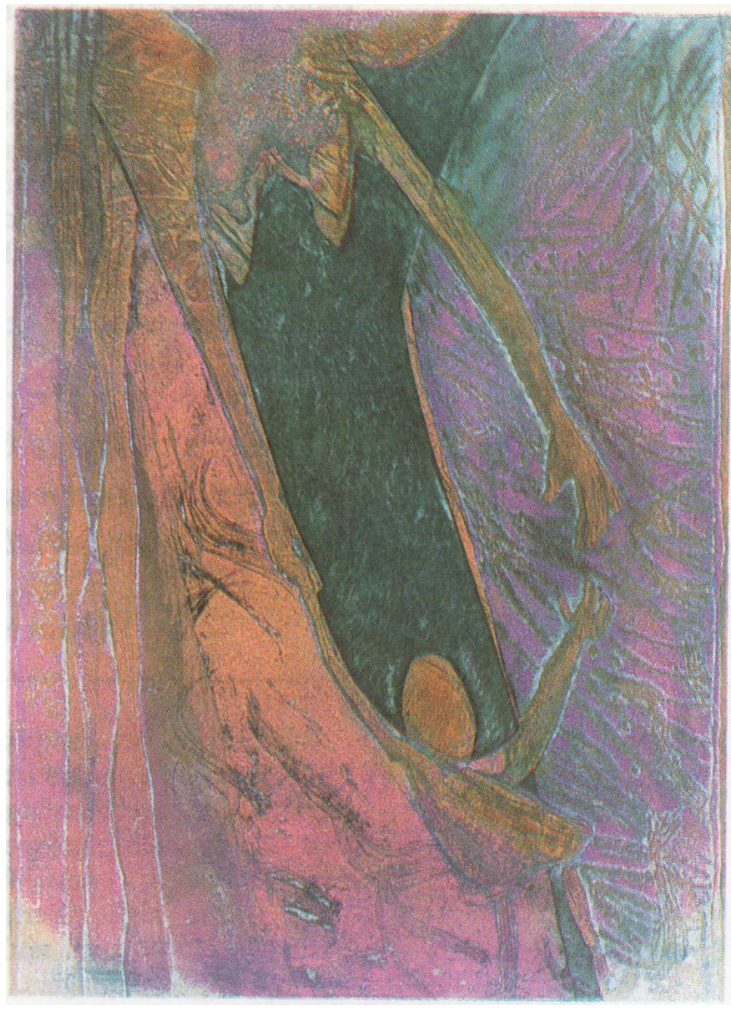

"Out of the Storm" by Meg Campbell (see p 1708)

thing he had ever experienced, but the complete indifference of officialdom did not surprise him as it did me and he thought that it was time to "go public." The last thing I wanted was to have the situation discussed publicly. My fear was that it could be trivialised, personalised, and perhaps made sensational with possible harm to patients and relatives rather than lead to the better, safer care I sought. My opinion of the national press and media (typical, I have come to realise, of most nurses) was far from complimentary and I did not want them involved. As it was to turn out, my cynicism was unfounded. I expressed my reluctance but agreed to give his suggestion some thought. My efforts over two years had proved futile so was I to resign or continue with what seemed to be a hopeless cause? So far as I was concerned silence was never an option. I resolved to continue.

On 11 April 1990 the Guardian published extracts from the correspondence, and other newspapers, the nursing press, and the broadcasting media began to take an interest. It did not cross my mind for a moment that anyone, and certainly not senior nurses, would want to punish me for insisting on decent standards of patient care and doing all that seemed reasonable to attain them. I did not realise that what I thought was a imperishable right of freedom of speech in Britain was as fragile and vulnerable as the health and safety of those I sought to protect. I was being open and honest in describing what $I$ had seen. This is something that nurses are often unable or unwilling to do. But for me truth and a confidence that the UKCC would defend me were my shield. I could not have been more wrong. The shield was a colander, and telling the truth was the rope that hanged me.

\section{An unforgettable $\mathbf{4 0}$ minutes}

Just how different the situation could be was vividly brought home to me one night when a nurse from the intensive care unit, which had only one patient, was sent to help. At about $930 \mathrm{pm}$ Mrs $\mathrm{H}$ telephoned, as she had done on the two previous evenings. She was in some distress. Her husband was a patient and she had been told earlier in the day for the first time that he was 
terminally ill with cancer, though she was not aware that he knew. She told me that they had been married for 52 years and that their handicapped son, the only child, had died the year before. Now she was alone with no other relative and knew that she was about to become a widow. We spoke for 10 minutes or more and I think that I said all the right things. She seemed to gain some comfort from my reassurance that her husband was settled, pain free, and would be constantly watched through the night-quite untrue, but perhaps justifiable in the circumstances.

Once the main task of settling the patients down was completed-so much quicker and more dignified with two nurses: amazingly, the lights were out by $1030 \mathrm{pm}-\mathrm{I}$ took the opportunity to go to $\mathrm{Mr} \mathrm{H}$ and sit with him. I told him of his wife's call and this encouraged him to speak of his fears and concernsnot for himself, but for his beloved wife. He did not know that the doctor had given her the news and he was anxious to protect her from too much suffering. "We've had 52 years of love and happiness," he said. "Now it's time to part." And over the ensuing 40 minutes he recalled so many memories of what must have been a remarkable partnership. He did most of the talking. I doubt if I have ever spent a more poignant yet worthwhile 40 minutes and I was so thankful that the main lights were out. As we clasped hands, the morphine took effect and he drifted into sleep.

$\mathrm{Mr} \mathrm{H}$ did not regain consciousness and died the following night, his sweetheart of well over half a century at his bedside. So my conversation with this brave and selfless man was his last on earth. While the demands and pressures of our work could be oppressive, the rewards were sublime. What a privilege and honour it was to be so close to $\mathrm{MrH}$ at such a time. By sacking me the health authority was to take away my job and my livelihood and put me through two years of great torment, but they could never take away the deep fulfilment and joy I was blessed with while caring for those patients. I have something more precious than a job or wages or security and if I achieve nothing else in the rest of my days the memory of those 40 minutes will suffice.

\section{A cruel dilemma}

In June 1990 I reported three senior nurses to the UKCC for professional misconduct. I pointed out that the charges concerned perceived, serious, and blatant neglect of patients and disregard for the health and welfare of the night staff. To help the council I

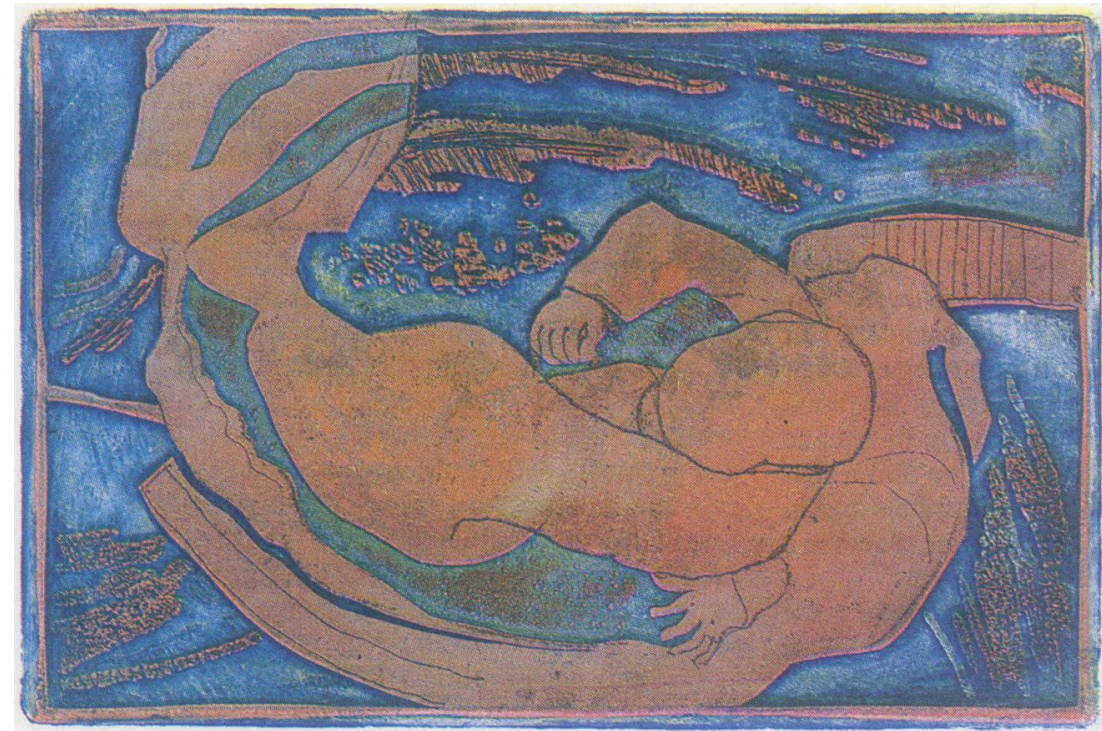

“Mother and Child" by Meg Campbell (seep 1708) provided a mass of evidence: statistics, reports, descriptions of incidents, correspondence, etc. The council passed the information to its investigating body, the English National Board For Nursing, Midwifery And Health Visiting (ENB).

British nurses have a code of professional conduct. The first clause of the code reads: "Act always in such a way as to promote and safeguard the wellbeing and interests of patients." Clause 11 enjoins me to have "regard to the workload of and pressures on professional colleagues and subordinates and take appropriate action if these are seen to be such as to constitute abuse of a nurse and/or jeopardise safe standards of practice." Clause 10 charges me to bring to managers' attention any circumstances which "could place patients in jeopardy."

The code looks impressive on paper but has no legal standing. It can be and often is ignored by managers. Yet failure to keep the code can lead to removal from the professional register. Thus nurses face a cruel dilemma-keep your code or keep your job.

The charges I made related specifically to clauses 1 , 2,10 , and 11 of the code. Of course, it would be necessary for the UKCC or the ENB to make detailed inquiries. The evidence of one person, as detailed as it was, could present only one side of the picture. Nor was I saying that these nurses were guilty. That was not for me to decide. But there clearly was a case to answer.

\section{Outrageous neglect}

The last straw came one particularly fatiguing and demanding night in June 1990 - a night deeply etched into my memory. It was $430 \mathrm{am}$. Our nursing auxiliary was on her second break and I was alone on one half of the ward (a ward made up of smaller rooms and areas) alone, that is, with 13 very ill, helpless patients, at least eight of whom were awake and needing attention, treatment, or restraint. My colleague on the other side, some $30 \mathrm{~m}$ away, out of sight and earshot, was just as occupied as was I. As I tried to prevent $\mathrm{Mr} \mathrm{B}$ from climbing out of his urine soaked bed and falling to the floor, another patient called out. $\mathrm{Mr} \mathrm{V}$, an 82 year old dying man, wanted to use his urinal but could not stand unaided. In the last stages of cancer of the stomach, he would not have looked out of place in Belsen. Mr B had a pulmonary embolism which caused him to cough up blood. This symptom upset him and, as the condition progressed, he became agitated and confused. He was attached to a heparin infusion pump, and to leave him at that moment for more than a few seconds was to expose him to considerable risk of injury. Mr V's plaintive cries continued, as distressing and pitiful to me as anything I have ever experienced.

Once $\mathrm{Mr} \mathrm{B}$ had quietened, I hurried round the partition to find $\mathrm{Mr} \mathrm{V}$, a quiet and gentle man, lying on the floor in a pool of urine, sobbing. It was a sight that caused me the utmost revulsion and upsets me each time I write about it. As I lifted the emaciated man I seemed to carry a much greater burden: a sense of shame that $I$, a registered nurse, should be forced to witness, nay inflict, such outrageous neglect on a dying man. And $\mathrm{Mr} \mathrm{V}$ could be forgiven if he imagined that he was in southern Poland in the 1940s and I some white coated guard about to inflict further brutality on him. As I laid down the inmate of block A14 no words could have expressed the disgust and rage which racked my whole being.

For nearly a year I had brought to management's attention, in as precise and honest a manner as I could, one bedside nurse's assessment of a disturbing situation. Clearly this latest incident would be treated with similar indifference. My duty now to the future patients of Stockport and their relatives seemed clear enough. Never again did I want to see a patient so 
humiliated and ill used. The people of the area had a right to know what was going on in a public hospital paid for by their taxes and in their name.

A few days after $\mathrm{Mr} \mathrm{V}$ died I visited the local paper and described his last hours and my utter despair and disgust. Within a week of the paper going to press I was suspended on four charges, the main one being breach of confidentiality. There was no breach of confidentiality. I did not disclose any patients' names. Obviously the health authority did not want people to know what was happening in their district NHS hospital with a service vital to the community. I had committed the unforgivable crime-breaking not confidentiality but secrecy. Suspension in August 1990 was intended to exclude, discredit, and silence me. It had nothing to do with caring for or protecting patients.

\section{Hostile and aggressive hearing}

That autumn I was put through a hostile, non-judicial, aggressive, and prejudicial disciplinary hearing that would have shocked the Queen Of Hearts. Two of the three members of the tribunal had been closely involved in the case and I had been less than complimentary about their apparent disinterest. The whole hearing was carried out in an accusatory manner. The proceedings, held of course behind closed doors, were more akin to a court martial with the accused facing charges of sedition and consorting with the enemy, which is how nurse managers often see the media. Of course, it was imperative that I be got rid of, so the rules of natural justice were trampled underfoot in the headlong rush to remove this insubordinate nurse who refused to keep his mouth shut.

I was declared guilty on all four counts and denounced as incompetent, without ever being so charged, by the health authority. One of the charges was that I had not signed for quinine sulphate, and this was deemed to constitute "gross misconduct." My deep disquiet about drug administration had been conveyed to management, urgently and repeatedly, for many months. My warnings were ignored. Now, management induced deficiencies were being used against the very person who had brought them to light. What is more, over a period of two years I had exposed and reported a considerable number of drug related errors-morphine sulphate and pethidine incorrectly injected; improper and dangerous drug administration by senior nurses; over half the patients in the ward incorrectly identified; carelessness with intravenous infusions; and vital care neglected. None of these situations was denied, yet no disciplinary action was taken against anyone else, despite patients' wellbeing, recovery, and even lives being at times placed in considerable danger.

The public outcry against my treatment was quite amazing. Letters flooded in to the Guardian, the nursing press, the health authority, members of parliament, and to me. So many were from nurses and relatives of elderly patients who described what they had witnessed or been obliged to be party to. I was moved and disturbed by what I read. I was aware only of the neglect and maladministration in Stockport, but the correspondents brought a whole new perspective of incompetent and often repressive nursing administration and services for care of the elderly in decline because of insufficient staff. I am now in no doubt that care of the elderly in many wards and hospitals and in parts of the community is poor and in some places is a disgrace.

I am sure that because of the public concern the authority offered me a post as a community nurse rather than sack me outright, which it clearly would have preferred to do. This was depicted in a press release as a generous offer by a concerned management not wishing to put me out of work. In reality, it was a face saving device but obviously not properly thought through. A nurse, found guilty of four counts of gross misconduct (including a drug related error), branded as incompetent by his immediate nurse managers and the authority chairman, was thought to be a fit and proper person to enter the homes at night of sick patients and those who were terminally ill and care for them alone and unsupervised.

Community nurses were quite rightly up in arms at the apparent denigration of their profession which the offer implied. But more to the point is what the offer said about managers' attitude to elderly patients sick at home if an unsafe nurse could be let loose on such vulnerable people. That highly paid health service managers could make such a blunder tells us a great deal about their style of management.

I would have loved to nurse in the community on a one to one basis, and in other circumstances I would have jumped at the opportunity. To care for people during their last days in their own homes must be a great privilege. I can think of no greater honour. But to accept the post would have meant sanctioning management's handling of the case and this was out of the question. Thus on 17 September 1991 I was sacked from my job-sacked for trying to improve patient care by speaking the truth. Rather than agree to some squalid bargain, I preferred what Lear offered honest Cordelia with the words, "Thy truth then be thy dower." From start to finish the whole business was a mockery of British traditions of fairness, decency, legality, honesty, truth, and justice - a stark travesty of all that is right, proper, and moral.

\section{Climate of fear}

The NHS belongs to the British people. The first duty of those who work in the service is to their patients. But the management of nursing is too often based on fear. The message to nurses is: "Keep your heads down, your mouths shut, and question nothing." Over recent years matters seem to have gone from bad to worse. Managers have become more defensive, remote, and inflexible. Many hospitals, almost all run by non-nurses, are imposing gagging clauses on staff, not to protect patient confidentiality

\section{"I estimate that the authority spent some $£ 500000$ of taxpayers' money 'defending the indefensible.' "'}

but to impose secrecy. They are there primarily to protect management against the honest concerns of medical and nursing staff for decent professional standards. We, the nurses, are there at the bedside, day and night, as no one else is. We are better placed than anyone to ensure that the care that the NHS provides meets patients' neéds and expectations and does so to an acceptable professional standard. But we are being silenced by evasive, gutless managers and undemocratic structures. These structures stifle public debate about staffing levels and standards of care. The untruth and prejudice of officialdom protected the guilty in my case and ensured the ousting of an innocent nurse, but I was left in no doubt about how the mass of ordinary, decent folk in Britain felt about my stand. Over 3000 letters arrived, an overwhelming vote of confidence by any standard.

The industrial tribunal ruled in June 1993 that I had been unfairly dismissed. I chose not to pursue reinstatement. I estimate that the authority spent some 
$£ 500000$ of taxpayers' money "defending the indefensible,"touse thewords ofmy defending Queen's Counsel, $\mathrm{Mr}$ John Hendy. While it claimed to have dismissed me for "breach of confidentiality" (no patient was ever named), Mr Hendy saw through this. "It is plain," he stated, "that the real reason Mr Pink was sacked was because he complained publicly about lack of nurses. Criticism is something the health authority was not prepared to tolerate. Throughout, Stockport's behaviour has been patently and crudely unfair."

After the industrial tribunal I sent additional detailed evidence to the UKCC regarding my allegation of misconduct of the nurse managers. The council claims that one of its principal aims is to serve the public interest by safeguarding "standards and quality of care available for members of the public at times of great dependence and vulnerability." My experience, and that of so many nurses who have contacted me, suggests that this is simple hogwash.
The council found that the Stockport nurse managers had no case to answer, in effect approving their conduct and seeing their behaviour correct in every particular. Any council members who believed that there was not even a case to answer is in my view a disgrace to themselves, the council, and the profession.

Speaking in the House of Commons on 17 June 1993 of the health authority's capitulation at the industrial tribunal, the prime minister implied that justice had been done. I fail to see by what perversion of language the outcome could be described as "justice." In view of management's rampant cynicism throughout, fully supported by central government, Oscar Wilde's aphorism, "A cynic is a man who knows the price of everything and the value of nothing," seems particularly apt. While so many people in Britain believe that the values of health service managers and their political masters must be questioned, I can certainly tell you the price of truth.

\title{
A passage through grief-the Western Australian Rural Pregnancy Loss Team
}

\author{
Simon Knowles
}

It's a dark wet chilly winter morning on the runway at Perth domestic airport. The Western Australian Rural Pregnancy Loss Team clambers into one of those small planes with odd rows of seats, two on the right and one on the left of the aisle. Makes you wonder why they don't fly lopsided; right wing down a bit. I don't really have that much attention to devote to aerodynamic theory because I've got a complete set of fingernails digging into my upper arm: Helen, a founder member of the roadshow, past president of the Western Australia chapter of SANDS-Stillbirth and Neonatal Death Support; a speech pathologist by trade. She has a serious fear of flying and the plane will soon echo to the combined sounds of turboprops and Helen, screaming in concert. The others in the team are Robert, Sue, and Elena. We are taking the roadshow to a country town in Western Australia. The plane speeds, relatively, down the runway. Helen, some speechie, utters inarticulate but irreverent comments at the top of her voice and tonal range. Robert, a hospital chaplain in civvies, indicates through sign language that she's certainly not with him. Not for the first time, I wonder what on earth we are doing.

According to our application to Healthways, the Western Australian Health Promotion Foundation, what we are doing is "diminishing the morbidity associated with miscarriage, stillbirth, and perinatal loss in rural Western Australia by promoting local support groups and transferring appropriate skills, attitudes, and knowledge to local caregivers." According to Helen, what we are doing is exposing ourselves to serious physical danger in the air and to the risk of cirrhosis, or worse, on the ground.

\section{The situation}

Anyone who has experienced it knows that the death

King Edward Memorial Hospital, Subiaco, Western Australia 6008, Australia

Simon Knowles, perinatal pathologist and head of laboratory services women after the death of their husbands, she concluded that the loss of a baby can have as severe an effect on the mental and physical health of a woman as the loss of a husband. In many cases a woman sees her miscarriage, stillbirth, or preterm labour as the first time that her body has let her down, providing a further reason for grief, guilt, and anger. The consequences transcend the loss of the infant and have a significant impact upon the parents, other siblings, extended family, and wider community. Morbidity is substantial. Perhaps as important, it is largely unrecognised.

The magnitude of the problem is considerable. In Australia, early pregnancy loss occurs in at least one of every 10 first pregnancies, and over one in 10-15 pregnancies subsequently. Western Australia has about 25000 live births a year. Additionally, of all registered births in Western Australia 4.6/1000 are stillborn and 4.2/1000 die in the perinatal period, representing over 200 babies a year across the state, of whom at least $60 \%$ are from country communities. The emotional impact of a pregnancy loss exerts an influence over years; the cumulative effect on our community is huge.

The situation is not made any easier in country areas. The state covers over two and a half million square kilometres, which makes it 10 times the size of the United Kingdom. Although most of our 1.6 million residents live within easy shout of the centre of Perth there are around 250000 people strung around the state from Albany in the south up to Derby and Broome in the far north. Owing to an excellent but intensely centralised tertiary obstetric service, many losses to rural families actually occur in the metropolitan area. We have a low threshold for intrauterine transfer via the Royal Flying Doctor Service. This has been a most successful strategy and serves rural areas very well. But a significant number of preterm infants are born, live, and die within the walls of a teaching hospital. Their families return to communities who have not shared the events surrounding the loss. Especially in the mining towns, personal isolation is intensified by the transient nature of the population; this often means transient health professionals and thus there may not be local expertise to deal with the social and emotional consequences of fetal death. 